\title{
The Ubiquity Nature of Acetylcholine
}

\section{Carlota Saldanha* and Ana S Silva-Herdade}

Instituto de Bioquímica, Instituto de Medicina Molecular, Faculdade de Medicina da Universidade de Lisboa, Portugal

*Corresponding author: Carlota Saldanha, , Tel: 351217922600; carlotasaldanha@fm.ul.pt

Received:April 26, 2014;Accepted:May 27, 2014;Published: May 31, 2014

Copyright:@ 2014 Saldanha C, et al. This is an open-access article distributed under the terms of the Creative Commons Attribution License, which permits unrestricted use, distribution, and reproduction in any medium, provided the original author and source are credited.

\section{Background}

Acetylcholine (ACh) was viewed as the "vagusstoff" after Loewi's experiment with the frog heart [1]. In 1936 Otto Loewi, and Henry Dale were recipients of the Nobel Prize in Physiology and Medicine, by their contribution for the acetylcholine discover as a neurotransmitter [1]. So, ACh was regarded as a neurotransmitter during several decades [2]. After that it was evidenced a widespread expression of the cholinergic system within a variety of non-neuronal tissues. The "Non-Neuronal Cholinergic System" (NNCS) is well established as the extra-neural effects of acetylcholine [3]. Beyond these neural and non neuronal cholinergic systems there is another one named by Tracey et al. as the Cholinergic Anti-Inflammatory Pathway (CAIP) [4]. Afferent and efferent signals transmitted in the vagus nerve are components of a neural circuit that modulates the innate immune response. The CAIP could be considered as a liaison between the cholinergic neural system and NNCS.

The enzymes implicated in the synthesis and responsible for hydrolysis of ACh in different mammalian cells are isoenzymes of Choline-Acetyltransferase (ChAT), and Acetylcholinesterase (AChE) respectively [5]. ACh is synthesised in the nerve cell from choline and acetyl-CoA by a process mediated by choline acetyltransferase and is stored in vesicles in pre-synaptic neurons [2]. Upon arrival of the nerve impulse, a membrane depolarisation is induced and ACh is released to the synaptic cleft. At postsynaptic membrane, ACh binds to its cholinergic receptor, initiating a cascade of actions that are stopped by the enzyme AChE, which hydrolyses ACh to Choline (Ch) and acetic acid [2]

\section{Non-Neuronal Cholinergic System (NNCS)}

Circulating acetylcholine can be produced by T-lymphocytes and endothelial cells $[6,7]$.

Lymphocytes express most of the cholinergic elements and upon interaction with the antigen presenting cells or the endothelial cells, $\mathrm{T}$ cells synthesize and release acetylcholine [8]. The autocrine ACh action depends on cell membrane receptor and in case of TCR/CD3 receptors for example enhances the expression of both ChAT and M5 mACh receptors [8].

At the vascular wall the ACh produced by the endothelium acts through the auto-paracrine fashion in the intrinsic intima [5]. All the neuronal components, ACh, ChAT and VAChT and AChE above mentioned, are also present in the NNCS [9].

We are the first to perform the biochemical characterization of the AChE in endothelial cell membrane of human umbilical vein. We have identified, with C-terminal anti-AChE, the expression of one molecular form membrane with $70 \mathrm{kDa}$, (the molecular mass characteristic of the human monomeric form of AChE). When the Nterminal anti-AChE was used two molecular forms with approximately $66 \mathrm{kDa}$ and $77 \mathrm{kDa}$ are expressed at membrane bound level [10]. The molecular form of $70 \mathrm{kDa}$ is also expressed at cytoplasm and nuclear compartments, where the latter also expressed an AChE isoform with approximately $55 \mathrm{kDa}$ [11]. We verified that the nuclear expression is not endothelial cell-specific but is also evidenced in nonneuronal and neuronal cells [11].

The widespread expression of non-neuronal acetylcholine is accompanied by the ubiquitous presence of acetylcholinesterase and nicotinic/muscarinic receptors. Red blood cells account for the blood elements with highest expression of membrane-bound acetylcholinesterase [12]. The enzyme AChE has the particularity to be inhibited by high concentrations of its own substrate, ACh. So, different types of enzyme complexes may be presented namely, active, inactive and less active ones according the amount of ACh existent [13].

Fuji and co-workers quantified the levels of ACh in plasma and blood at normal physiological conditions, and verified differences of its amount among animal species [14]

The circulating ACh induces vasodilation in dependence of integrity of the endothelium via the Nitric Oxide (NO) synthesised and released to smooth muscle $[15,16]$. Also the NO released from endothelial cells can move to the lumen of the vessels where is scavenged by erythrocyte and free hemoglobin present in the blood circulation [17]. The NO-Heme Hemoglobin adduct (HbFe (II) NO) has been detected during NO inhalation therapy used for pulmonary hypertension relief, but it also occurs when deoxygenated blood enters into a vascular bed in which $\mathrm{NO}$ is produced such as the pulmonary circulation $[18,19]$.

Low tissue oxygen tension is perceived by erythrocytes with induced hemoglobin structural allosteric transitions favouring the transfer of its NO bound molecule to band 3 that allow the NO efflux to the tissues in the capillary bed $[20,21]$. Among the heterotrophic effectors of oxygen binding hemoglobin, NO binds to the thiol group of cysteine $\beta 93$ at high tissue oxygen tension. At low tissue oxygen tension there is a NO release from either S-nitrosothiol of the Snitrosated hemoglobin or from the reduction of the anion nitrite to NO in a non exclusive way $[22,23]$. It is known that the $\mathrm{T}$ state of $\mathrm{SNO}-\mathrm{Hb}$ promotes the transnitrosation by which $\mathrm{NO}$ groups are transferred to thiol acceptors biomolecules in RBCs [24]. One of these is the protein band 3 [25], but the exact mechanism by which NO escape from erythrocyte membrane still remain uncertain.

We have verified that in presence of ACh there is an increased of the erythrocyte deformability, of the nitrite and nitrate concentration and the oxygen hemoglobin affinity and a decreased of erythrocyte aggregation $[26,27]$.

The lower erythrocyte deformability expressed in blood samples obtained from hypertensive, hypercholesterolemic and kidney 
Page 2 of 3

transplant patients was ameliorate when in presence of ACh as we verified by studies conducted in vitro [28].

Non-neuronal acetylcholine appears to be involved in the regulation of elementary cell functions such as cell mitosis, cell-cell interaction, cell automaticity, locomotion, ciliary activity, barrier function, resorption and secretion [29-33]. In the airways, for instance, the great majority of cells express the components of NNCS and it is documented that a substantial increase on ACh levels triggers the release of proinflammatory effectors [34]. In addition, the excitability of airway mast cells can be powerfully inhibited by acetylcholine [35].

\section{The Cholinergic Anti-Inflammatory Pathway (CAIP)}

The vagus nerve innervates major organs, including the spleen and the gut, regulates physiological responses to stress, injury and infection. It was observed that the action potential transmitted in sensory nerve fibers to the brain reports the presence of inflammatory stimuli in peripheral issues [14].

The electric stimulation of the vagus nerve enhances the release of acetylcholine from the spleen [36]. Several studies using immumohistochemistry, electron micrsoscopy and neurophysiological techniques [37,38] demonstrate communication between the nerve endings and the $T$ cells, $B$ cells and macrophages that lead to antiinflammatory signals through the efferent vagus nerve. Tracey et al. based on his work proposes the cholinergic anti-inflammatory pathway [39-41]. It consists in the activation of adrenergic neurons in the spleen that liberate nor-epinephrine near the $\mathrm{T}$ cell capable to secrete acetylcholine. This pathway plays a critical role in controlling the inflammatory response through ACh interaction with peripheral a7 subunit-containing nicotinic acetylcholine receptors expressed on macrophages which suppress the synthesis and secretion of inflammatory cytokines. Macrophages act as an interface between the brain and the immune system [4] by the participation of its JaK2/ STAT3 signal pathway or via inhibition of the transcription factor NF$\mathrm{kB}[42,43]$. So, a crosstalk is established between the immune system and the central nervous system that contribute for the reposition of homeostasis in the former.

The activation of afferent vagus nerve by endotoxin or proinflammatory cytokines stimulates hypothalamic-pituitary-adrenal anti-inflammatory responses conducted by the efferent vagus nerve [44].

Acetylcholine is an anti-inflammatory molecule that suppresses the production of pro-inflammatory cytokines [3] suggesting that the neuronal activation of the adrenergic system, for example in spleen, release nor-epinephrine from the efferent fibers near $\mathrm{T}$ cells which became able to liberate non neuronal acetylcholine. In consequence this ACh interacts with $\alpha 7 \mathrm{nAChR}$ expressed on cytokine production macrophages. The extraneuronal cholinergic system in lymphocytes is responsible for the levels of acetylcholine in blood circulation [6]. In the case for example of nicotine application it generates complex effects in dependence of the route or local of its administration $[45,46]$.

\section{In vivo Experimental Studies of the Effects of $\mathrm{ACh}$ in Inflammatory Response}

The study done by Silva-Herdade and Saldanha was conducted in vivo on an animal model of Lipopolysaccharide (LPS) induced inflammation aimed to evaluate the effects of ACh on the leukocyteendothelial cells interactions and to quantify the concentrations of
TNF-alpha in blood circulation. Using intravital microscopy the number of rolling and adherent leukocytes in post-capillary venules of Wistar rats was registered after the intravenously administration of LPS alone or with further addition of ACh. Those results evidenced the anti-inflammatory effect of ACh showed by a decrease in TNFalpha plasma levels and by the decrease of the number of adherent leukocytes [47]. Taking in consideration the non neuronal origin of ACh that we mimesis in these in vivo studies we cannot exclude with sure the participation of the cholinergic anti-inflammatory pathway when LPS was administered.

In a previous study the same authors using the same animal model protocol but without induced inflammation showed decrease of the number of rolling and adherent leukocytes while the rolling velocity was reduced without changes in plasma levels of IL-1-beta [48].

We conclude that ACh has an anti inflammatory effect decreasing the concentration of TNF-alpha in plasma and the adhesion of the leukocytes to the endothelial cells that is one of the former steps in the inflammatory innate response. The acute inflammatory state implicated by the surgery show also the anti-inflammatory action of ACh that left unchanged IL-1-beta.

\section{Conclusions}

Apart from the former discovers of the neuronal action of acetylcholine much more different cellular locals of synthesis of ACh are evidenced which implicate diverse biological effects conferring its ubiquitous molecular behavior. For instance its ubiquity is different from that of coenzyme $\mathrm{Q}$ which moves inside the inner mitochondrial membrane occupying diverse places closer or away from one complex of the electron chain but with the same oxi-reduction function.

Acetylcholine acts in the parasympathetic system, in the neuron muscle junction, in the T-lymphocytes, in endothelial cells, in erythrocytes demonstrate the ability to bind and be recognized by a different membrane cell types. ACh induces in the endothelium the NO synthesis; when within the airway epithelium ACh is involved in the regulation of water and ion transport; acts as anti inflammatory agent when liberate by $\mathrm{T}$-cell activation increasing its concentration in blood circulation. In general terms, the biochemistry point of view that the structure of one biomolecule dictates its physiological function has been enlarged by a multitude of actions and effects resulting from the signal transduction pathway associated with their different kind of receptors or with the same type of receptors in distinct cells.

\section{Acknowledgment}

This study was supported by grants from the FCT-Fundação para a Ciência e a Tecnologia (EXCL/MAT-NAN/0114/2012).

\section{References}

1. Wittaker VP (1963) Cholinergic neurohormones. Comp Endocr 2: 182-208.

2. Michelson MJ, Zeimal EV (1973) Acetylcholine An approach to the molecular mechanism of action. Pergamon Press, Oxford, USA.

3. Wessler I, Kirkpatrick CJ (2008) Acetylcholine beyond neurons: the nonneuronal cholinergic system in humans. Br J Pharmacol 154: 1558-1571.

4. Pavlov VA, Wang H, Czura CJ, Friedman SG, Tracey KJ (2003) The cholinergic anti-inflammatory pathway: a missing link in neuroimmunomodulation. Mol Med 9: 125-134. 
Page 3 of 3

5. Wessler I, Kirkpatrick CJ, Racké K (1999) The cholinergic 'pitfall': acetylcholine, a universal cell molecule in biological systems, including humans. Clin Exp Pharmacol Physiol 26: 198-205.

6. Kawashima K, Fujii T (2000) Extraneuronal cholinergic system in lymphocytes. Pharmacol Ther 86: 29-48.

7. Kawashima K, Fujii T, Watanabe Y, Misawa H (1998) Acetylcholine synthesis and muscarinic receptor subtype mRNA expression in $\mathrm{T}$ lymphocytes. Life Sci 62: 1701-1705.

8. Kawashima K, Fujii T (2003) The lymphocytic cholinergic system and its contribution to the regulation of immune activity. Life Sci 74: 675-696.

9. Grando SA, Kawashima K, Kirkpatrick CJ, Wessler I (2007) Recent progress in understanding the non-neuronal cholinergic system in humans. Life Sci 80: 2181-2185.

10. Carvalho FA, Graça LM, Martins-Silva J, Saldanha C (2005) Biochemical characterization of human umbilical vein endothelial cell membrane bound acetylcholinesterase. FEBS J 272: 5584-5594.

11. Santos SC, Vala I, Miguel C, Barata JT, Garção P, et al. (2007) Expression and subcellular localization of a novel nuclear acetylcholinesterase protein. J Biol Chem 282: 25597-25603.

12. Wright DL, Plummer DT (1973) Multiple forms of acetylcholinesterase from human erythrocytes. Biochem J 133: 521-527.

13. Saldanha C (1985) Acetylcholinesterase Contribution for the kinetic study of the human erythrocyte enzyme. PhD Thesis, Universidade Nova de Lisboa, Portugal.

14. Fujii T, Yamada S, Yamaguchi N, Fujimoto K, Suzuki T, et al. (1995) Species differences in the concentration of acetylcholine, a neurotransmitter, in whole blood and plasma. Neurosci Lett 201: 207-210.

15. Furchgott RF, Vanhoutte PM (1989) Endothelium-derived relaxing and contracting factors. FASEB J 3: 2007-2018.

16. Zhou Y, Varadharaj S, Zhao X, Parinandi N, Flavahan NA, et al. (2005) Acetylcholine causes endothelium-dependent contraction of mouse arteries. Am J Physiol Heart Circ Physiol 289: H1027-1032.

17. Vaughn MW, Huang KT, Kuo L, Liao JC (2000) Erythrocytes possess an intrinsic barrier to nitric oxide consumption. J Biol Chem 275: 2342-2348.

18. Ignarro LJ, Byrns RE, Buga GM, Wood KS (1987) Endothelium-derived relaxing factor from pulmonary artery and vein possesses pharmacologic and chemical properties identical to those of nitric oxide radical. Circ Res 61: 866-879.

19. Sonveaux P, Lobysheva II, Feron O, McMahon TJ (2007) Transport and peripheral bioactivities of nitrogen oxides carried by red blood cell hemoglobin: role in oxygen delivery. Physiology (Bethesda) 22: 97-112.

20. Lane P, Gross S (2002) Hemoglobin as a chariot for NO bioactivity. Nat Med 8: 657-658.

21. Han TH, Qamirani E, Nelson AG, Hyduke DR, Chaudhuri G, et al (2003) Regulation of nitric oxide consumption by hypoxic red blood cells. Proc Natl Acad Sci U S A 100: 12504-12509.

22. Nagababu E, Ramasamy S, Abernethy DR, Rifkind JM (2003) Active nitric oxide produced in the red cell under hypoxic conditions by deoxyhemoglobin-mediated nitrite reduction. Journal Biological Chemistry 278: 46349-46356.

23. Stamler JS, Jia L, Eu JP, McMahon TJ, Demchenko IT, et al. (1997) Blood flow regulation by S-nitrosohemoglobin in the physiological oxygen gradient. Science 276: 2034-2037.

24. Jia L, Bonaventura C, Bonaventura J, Stamler JS (1996) S nitrosohaemoglobin: a dynamic activity of blood involved in vascular control. Nature 380: 221-226.

25. Pawloski JR, Hess DT, Stamler JS (2005) Impaired vasodilation by red blood cells in sickle cell disease. Proc Natl Acad Sci U S A 102: 2531-2536.

26. Mesquita R, Pires I, Saldanha C, Martins-Silva J (2001) Effects of acetylcholine and spermineNONOate on erythrocyte hemorheologic and oxygen carrying properties. Clin Hemorheol Microcirc 25: 153-163.
27. Carvalho FA, Mesquita R, Martins-Silva J, Saldanha C (2004) Acetylcholine and choline effects on erythrocyte nitrite and nitrate levels. J Appl Toxicol 24: 419-427.

28. Carvalho FA, Maria AV, Braz Nogueira JM, Guerra J, Martins-Silva J, et al. (2006) The relation between the erythrocyte nitric oxide and hemorheological parameters. Clin Hemorheol Microcirc 35: 341-347.

29. Sastry BV, Sadavongvivad C (1978) Cholinergic systems in non-nervous tissues. Pharmacol Rev 30: 65-132.

30. Wessler I, Kirkpatrick CJ, Racké K (1998) Non-neuronal acetylcholine, a locally acting molecule, widely distributed in biological systems: expression and function in humans. Pharmacol Ther 77: 59-79.

31. Kirkpatrick CJ, Bittinger F, Unger RE, Kriegsmann J, Kilbinger H, et al. (2001) The non-neuronal cholinergic system in the endothelium: evidence and possible pathobiological significance. Jpn J Pharmacol 85: 24-28.

32. Wessler I, Kilbinger H, Bittinger F, Unger R, Kirkpatrick CJ (2003) The non-neuronal cholinergic system in humans: expression, function and pathophysiology. Life Sci 72: 2055-2061.

33. Grando SA, Kawashima K, Kirkpatrick CJ, Wessler I (2007) Recent progress in understanding the non-neuronal cholinergic system in humans. Life Sci 80: 2181-2185.

34. Wessler I, Bittinger F, Kamin W, Zepp F, Meyer E, et al. (2007) Dysfunction of the non-neuronal cholinergic system in the airways and blood cells of patients with cystic fibrosis. Life Sci 80: 2253-2258.

35. Wessler IK, Kirkpatrick CJ (2001) The Non-neuronal cholinergic system: an emerging drug target in the airways. Pulm Pharmacol Ther 14: 423-434.

36. Brandon KW, Rand MJ (1961) Acetylcholine and the sympathetic innervation of the spleen. J Physiol 157: 18-32.

37. Niijima A, Hori T, Aou S, Oomura Y (1991) The effects of interleukin-1 beta on the activity of adrenal, splenic and renal sympathetic nerves in the rat. J Auton Nerv Syst 36: 183-192.

38. Niijima A, Hori $T$, Katafuchi $T$, Ichijo $T$ (1995) The effect of interleukin-1 beta on the efferent activity of the vagus nerve to the thymus. J Auton Nerv Syst 54: 137-144.

39. Borovikova LV, Ivanova S, Zhang M, Yang H, Botchkina GI, et al. (2000) Vagus nerve stimulation attenuates the systemic inflammatory response to endotoxin. Nature 405: 458-462.

40. Tracey KJ, Czura CJ, Ivanova S (2001) Mind over immunity. FASEB J 15: 1575-1576.

41. Tracey KJ (2002) The inflammatory reflex. Nature 420: 853-859.

42. de Jonge WJ, van der Zanden EP, The FO, Bijlsma MF, van Westerloo DJ, et al. (2005) Stimulation of the vagus nerve attenuates macrophage activation by activating the Jak2-STAT3 signaling pathway. Nat Immunol 6: 844-851.

43. Wang H, Liao H, Ochani M, Justiniani M, Lin X, et al. (2004) Cholinergic agonists inhibit HMGB1 release and improve survival in experimental sepsis. Nat Med 10: 1216-1221.

44. Watkins LR, Goehler LE, Relton JK, Tartaglia N, Silbert L, et al. (1995) Blockade of interleukin-1 induced hyperthermia by subdiaphragmatic vagotomy: evidence for vagal mediation of immune-brain communication. Neurosci Lett 183: 27-31.

45. Miao FJ, Jänig W, Levine JD (1997) Vagal branches involved in inhibition of bradykinin-induced synovial plasma extravasation by intrathecal nicotine and noxious stimulation in the rat. J Physiol 498 : 473-481.

46. Miao FJ, Benowitz NL, Levine JD (2001) Endogenous opioids suppress activation of nociceptors by sub-nanomolar nicotine. Br J Pharmacol 133: 23-28.

47. Silva-Herdade AS, Saldanha C (2013) Effects of acetylcholine on an animal mode of inflammation. Clin Hemorheol Microcirc 53: 209-216.

48. Silva AS, Saldanha C, Martins e Silva J (2007) Effects of velnacrine maleate in the leukocyte-endothelial cell interactions in rat cremaster microcirculatory network. Clin Hemorheol Microcirc 36: 235-246. 